\title{
THE ITEP POWERFUL HEAVY ION ACCUMULATOR (ITEP-TWAC) PROJECT - RECENT DEVELOPMENT AND PROSPECTS
}

\author{
N.N.Alexeev, D.G.Koshkarev, B.Yu.Sharkov, ITEP, Moscow, Russia
}

\section{Abstract}

The ITEP-TWAC is a new heavy ion accumulator facility under construction at Institute for Theoretical and Experimental Physics in Moscow. The project has done good progress in last year. Some of major milestones were successfully passed. The beam of $\mathrm{C}^{4+}$ ions delivered by the laser ion source was accelerated up to the energy of $300 \mathrm{MeV} / \mathrm{u}$ by two steps - in linear injector I3 and in booster synchrotron UK. The accelerated beam was extracted from the UK ring and transferred to the U10 accumulator ring. Non-Liouvillian stripping technique $\left(\mathrm{C}^{4+} \Rightarrow \mathrm{C}^{6+}\right)$ for stacking of $\mathrm{C}^{6+}$ batch into U10 accumulator ring was applied and successfully tested. Activities aiming to minimise beam losses on the pass from the ion source to the accumulator ring are underway. The beginning of the intense ion beam accumulation for beam dynamics studies as well as first experiment with extracted beam are scheduled for the fall 2001.

\section{INTRODUCTION}

The TWAC project $[1,2]$ is intended to initiate some groundwork for development and promotion of high intensity and high power heavy ion beam technology on the base of accelerator facilities available at ITEP. Issues like phase space density dilution processes by resonances and instabilities in rings, space charge effects in beam transport lines, pulse compression and pulse shaping, final beam focusing to experimental targets etc. can be investigated in the frame of TWAC Facility.

\section{TWAC LAYOUT}

Several stages of heavy ion beam treatment are provided in TWAC for a stacking of high power ion boublik in the U10 accumulator ring. The laser ion source is used for producing of highly charged ions (Z/A $0.25 \div 0.45$ ) with atomic mass of up to 60 and at extraction potential of $50 \mathrm{keV}$. Preliminary acceleration of ions is carried out in the linear injector I3 up to the energy of $1 \div 2$ $\mathrm{MeV} / \mathrm{amu}$. An energy of beam stacking (up to 700 $\mathrm{MeV} / \mathrm{amu}$ ) is reached in the booster synchrotron UK. After acceleration in UK, the ion beam is transferred into accumulator ring U10. The procedure of ion beam stacking in the accumulator ring U10 is based on a technique of Nonliouvillean charge exchange multiple injection proposed for heavy ion accumulation [1] and considered in details in [3]. Theoretically expected parameters of TWAC for different ion species are listed in Table 1. The values of output TWAC parameters given in table are estimated without taking into account intrabeam scattering effect in accumulator ring. The last one, as it

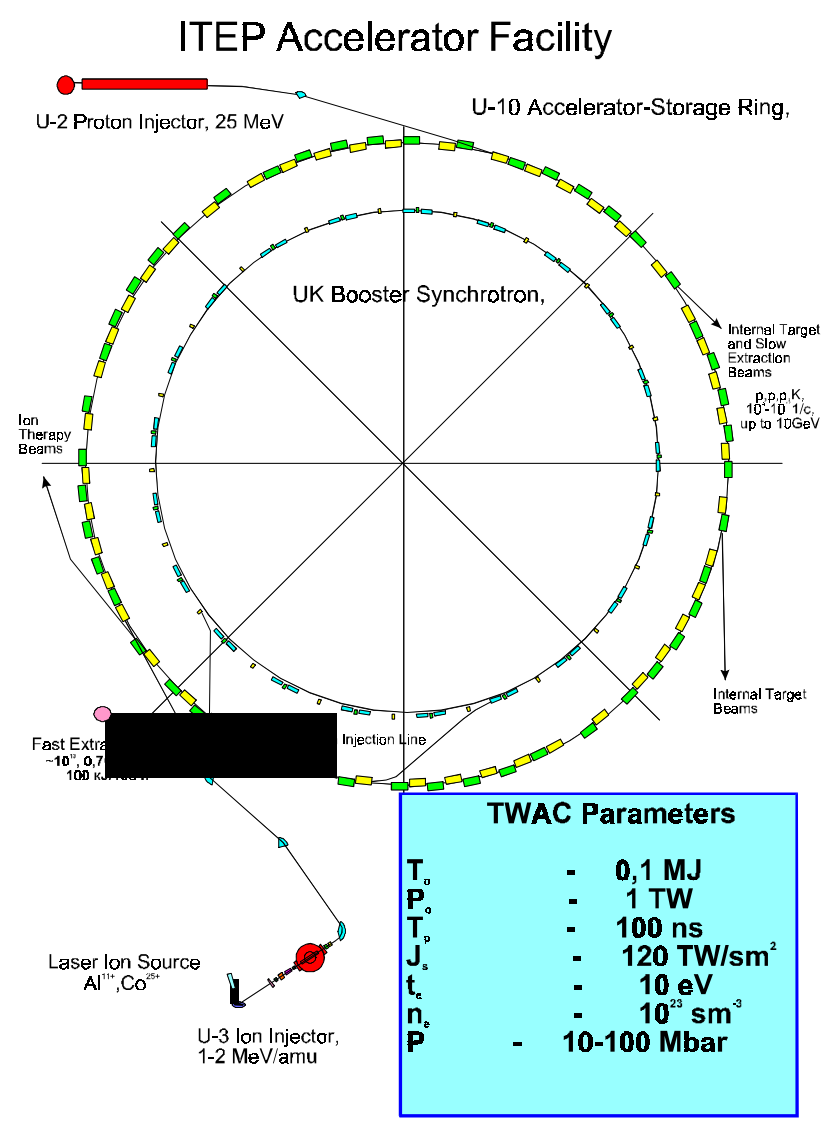

Figure 1: Layout of ITEP Accelerator Facility

was shown in [3], sets intensity limit at the value of $310^{12}$ for cobalt ions accumulating in U10 ring during $300 \mathrm{~s}$ with repetition rate of one $\mathrm{Hz}$. This limitation may be overcome by increasing the rate of accumulation process.

Table 1: Expected output parameters of the TWAC

\begin{tabular}{|l|l|l|l|}
\hline Ion type & ${ }_{12} \mathrm{C}^{4+=>6+}$ & ${ }_{27} \mathrm{Al}^{11+\Rightarrow}$ & ${ }_{59} \mathrm{Co}^{23+=>27+}$ \\
\hline $\mathrm{Z} / \mathrm{A}$ & $0.33 / 0.5$ & $0.41 / 0.48$ & $0.42 / 0.46$ \\
\hline Kinetic energy & $6 \mathrm{GeV}$ & $17 \mathrm{GeV}$ & $39 \mathrm{GeV}$ \\
\hline Velocity, $\beta / \gamma$ & $0.76 / 1.54$ & $0.80 / 1.68$ & $0.82 / 1.73$ \\
\hline Intensity in UK & $610^{10}$ & $310^{10}$ & $10^{10}$ \\
\hline Intensity in U10 & $410^{13}$ & $2.510^{13}$ & $1.310^{13}$ \\
\hline Beam energy & $30 \mathrm{~kJ}$ & $60 \mathrm{~kJ}$ & $100 \mathrm{~kJ}$ \\
\hline Beam power & $0.3 \mathrm{TW}$ & $0.6 \mathrm{TW}$ & $1 \mathrm{TW}$ \\
\hline
\end{tabular}

\section{TWAC STATUS}

The milestones on the road from ITEP Accelerator Facility to upgraded TeraWatt Accumulator are the following:

- upgrade of the ion injector I3 for a maximum of output beam current; construction of a new beam line and a injection system for UK ring; 
- commissioning of the booster synchrotron UK;

- construction of both fast extraction system for UK ring with beam line UK/U10 and multiple injection system for accumulator ring U10;

- commissioning of accumulator U10;

- construction of both fast extraction system for U10 ring and beam line to experimental hall;

- raising of accumulated beam intensity;

- installation of the $100 \mathrm{~J}$ laser ion source in the I3;

- construction of a new high current ion injector.

As it will be shown below, we are now on the second half of this outlined way.

\subsection{Ion source, injector I3, beam line I3/UK}

The layout of ion injector I3 upgrade is given in [4]. The $5 \mathrm{~J} \mathrm{CO}_{2}$ laser ion source with carbon target is used for generation of ions with charge states up to $(+5)$. As a result of last improvements in laser ion source optics, the total ion current at the I3 input was cardinally increased and reached more than $90 \mathrm{~mA}$ in peak (Fig.2). But very high unequality of current in beam pulse reduces essentially an efficiency of this beam utilisation.

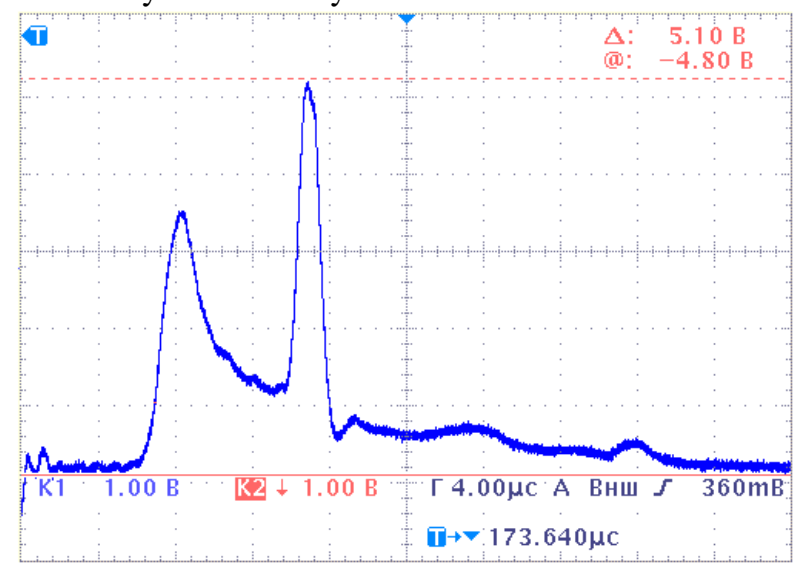

Fig. 2: The total carbon beam current at the input of the Injector I3 (1V/18 mA).

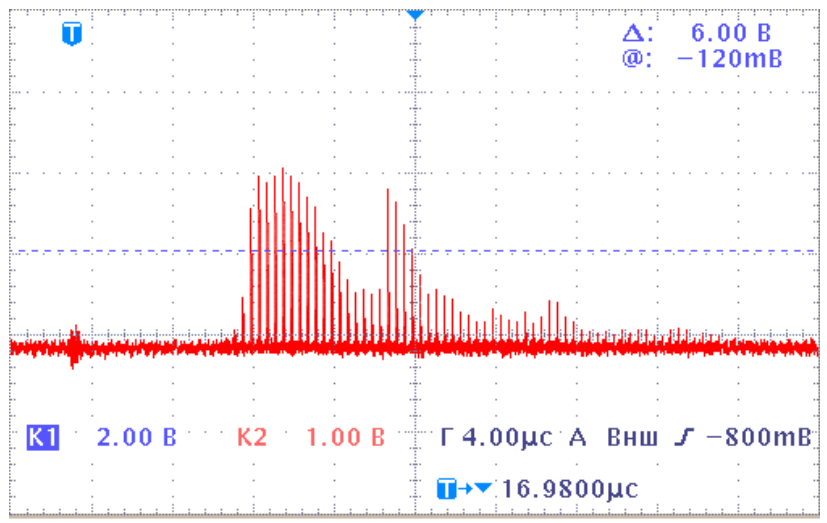

Fig. 3: The bunch structure of $\mathrm{C}^{4+}$ beam at the output of the Injector I3 $(1 \mathrm{~V} / 40 \mathrm{~mA})$.

The most intense species of the ${ }_{12} \mathrm{C}^{4+}$ ion beam with energy of $1.2 \mathrm{MeV} / \mathrm{amu}$ is separated at the output of the
I3 injector for acceleration in UK. Maximum current of the $\mathrm{C}^{4+}$ beam at the output of injector $\mathrm{I} 3$ reaches $5 \mathrm{~mA}$ what corresponds to the limit of the current value for this accelerating structure.

Beam line I3/UK is not fully optimised now, so we have't more than $2 \mathrm{~mA}$ of the $\mathrm{C}^{4+}$ ions at the input of booster synchrotron. Beam losses in transfer line is caused by defocusing Coulomb forces in high charge density bunches and insufficient rigidity of the beam transfer channel.

\subsection{Booster synchrotron UK}

The BS UK is intended for acceleration of partially stripped ions with energy span from $1.2 \mathrm{MeV} / \mathrm{amu}$ up to $700 \mathrm{MeV} / \mathrm{amu}$ (Table 2).

Table 2: Parameters of the booster synchrotron UK

\begin{tabular}{|l|c|}
\hline Orbit length, $\mathrm{m}$ & $223 \mathrm{~m}$ \\
\hline Magnetic rigidity, $\mathrm{T} \mathrm{m}$ & $9.8 \mathrm{~T} \mathrm{~m}$ \\
\hline Injection energy, MeV/amu & 1.2 \\
\hline Output energy, MeV/amu & up to 700 \\
\hline Vacuum, Torr & $510^{-10}$ \\
\hline RF tuning range, $\mathrm{MHz}$ & $0.6 \div 10$ \\
\hline RF amplitude, $\mathrm{kV}$ & 10 \\
\hline Hor. acceptance, $\pi \mathrm{mm} \mathrm{mrad}$ & 120 \\
\hline Ver. acceptance, $\pi \mathrm{mm} \mathrm{mrad}$ & 90 \\
\hline Repetition rate, $\mathrm{Hz}$ & 1 \\
\hline
\end{tabular}

The required RF modulation was obtained by means of using two cavities working in sequence and modulated in the frequency ranges of $0.6 \div 2.2 \mathrm{MHz}$ for the first and of $2.2 \div 10 \mathrm{MHz}$ for the second.

At the vacuum available now in the UK ring $\left(510^{-10}\right.$ Torr), the beam loss exponent is shown in Fig. 4. We are planing subsequent improvement of the vacuum in the UK ring twice or three times with installation of additional non-evaporable getter pumping.

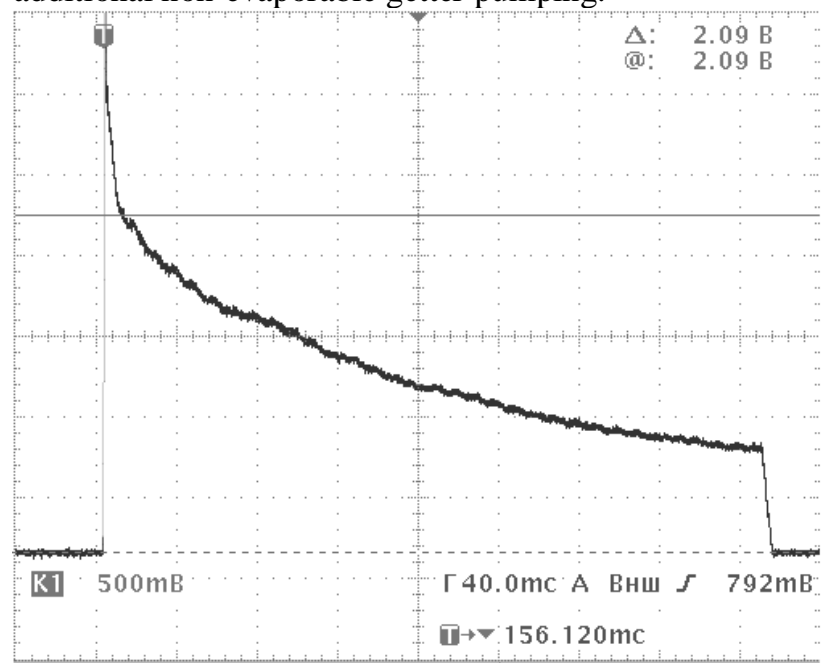

Fig.4: Oscilloscope trace of the $\mathrm{C}^{4+}$ beam intensity in the UK ring by acceleration, vacuum $\sim 510^{-10}$ Torr $\left(1 \mathrm{~V} / 210^{9}\right.$ ions)

\subsection{Beam fast extraction from UK}

The kicker magnet system with beam line were constructed and installed for the beam transfer from UK 
to U10. Kicker magnets for TWAC described in [5], the fragment of the beam line UK/U10 is shown on Fig.5.

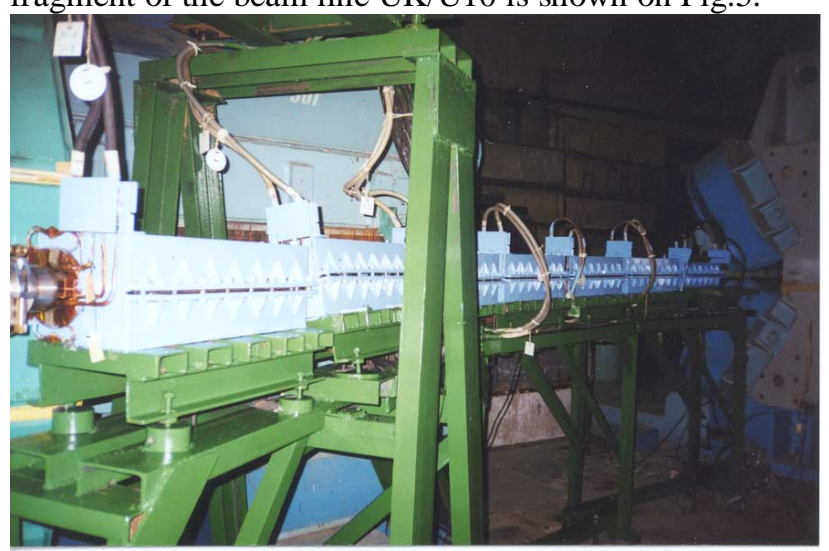

Fig. 5: The fragment of beam transfer line UK/U10 with bending magnets path.

\subsection{Charge exchange injection of ${ }_{12} \mathrm{C}^{4+}$ ions into accumulator ring $\mathrm{U10}$}

The ion accumulation procedure [3] is based on using both stripping foil and fast bump system in accumulator ring for minimising the coasting beam disturbance over

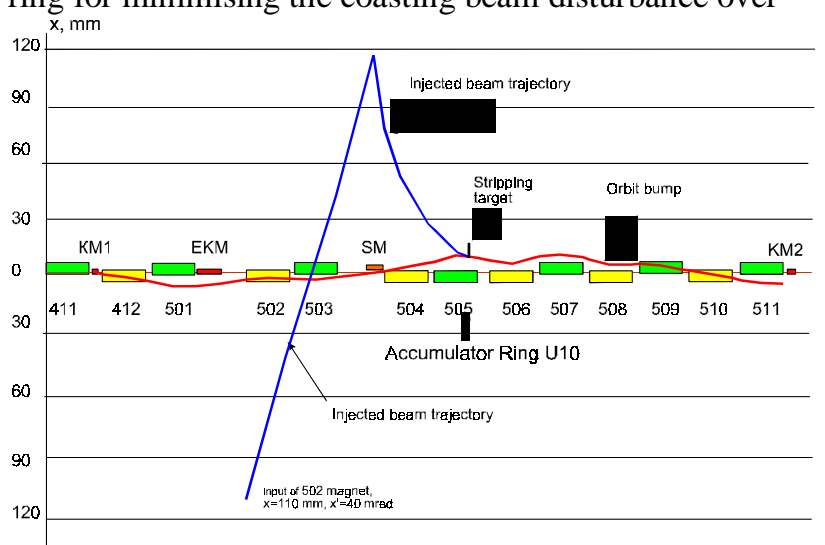

Figure 6: Charge exchange injection scheme for the Accumulator Ring U10

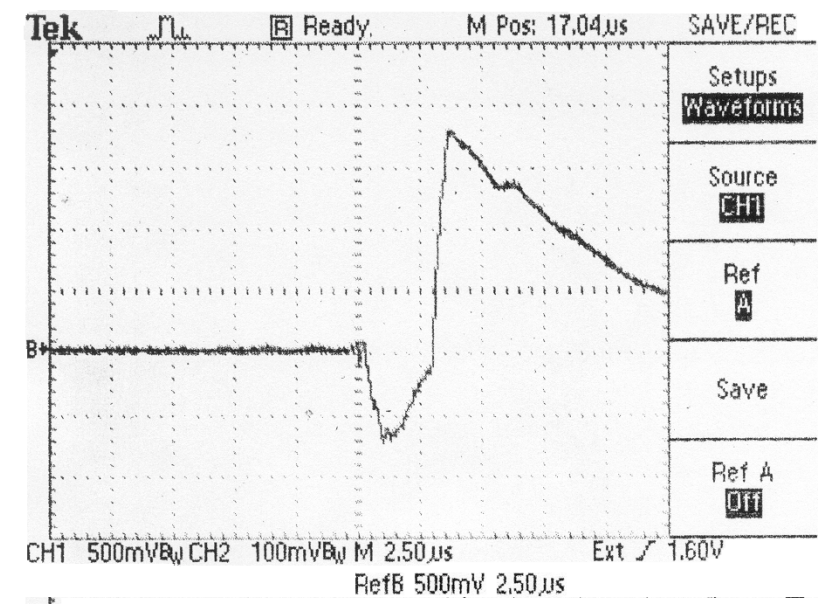

Figure 7: Oscillograms of the signal from stripping foil at the charge exchange injection of the $\mathrm{C}^{4+} \Rightarrow>\mathrm{C}^{6+}$ beam to the U-10 Accumulator Ring the particles penetrating through the stripping foil material. Three kicker magnets for the fast bump system have been installed in U10 ring in May 2001, and the whole equipment of this system is now under testing. We are planning to start complex adjusting of the multiple injection with ${ }_{12} \mathrm{C}^{4+}$ ions in July 2001. The first result of testing the charge exchange injection of the ${ }_{12} \mathrm{C}^{4+}$ beam into the U-10 ring is shown in Fig.7.

\section{OUTLOOK FOR TWAC ADVANCE}

Mastering the multiple injection for ion accumulation is the main problem to be solved for successful progress of TWAC project. We have just done the first step on the road to this new technology. The results of subsequent experiments with carbon ion accumulation scheduled for summer and fall of 2001 will give us more detailed understanding of the features on this sophisticated technique.

The problems of ion beam intensity at the output of booster synchrotron are more technical than theoretical and technological so they will be get over step by step to the Coulomb limit. The smoothing of current density at the output of laser ion source and a lengthening of beam pulse (Fig.2) has to be done by reducing the peak value of current. The beam loss in the booster synchrotron (Fig.4) results from both: for lack of dynamic correction of the ring magnetic field and insufficient vacuums in the UK ring. Twice increase of the UK intensity will be obtained by implementing the adiabatic capture of the injected beam.

The low energy of the beam injected to booster synchrotron remains the main limit for the subsequent beam intensity increase. So, the project of a new linear ion injector for UK is now under consideration. Output parameters of new injector are listed in Table 3.

Table 3: Project parameters of new ion injector for TWAC

\begin{tabular}{|l|c|}
\hline Output energy, MeV/amu & 7 \\
\hline RFQ frequency, MHz & 81 \\
\hline Z/A & $0.3 \div 0.4$ \\
\hline Acceptance, $\pi \mathrm{mm} \mathrm{mrad}$ & $>200$ \\
\hline Repetition rate, $\mathrm{Hz}$ & 10 \\
\hline Current limit, $\mathrm{mA}$ & 20 \\
\hline
\end{tabular}

\section{REFERENCES}

[1] D.G.Koshkarev et al., "ITEP Accelerator Facility Upgrade", XV Workshop on Charged Accelerator, Protvino, October 1996, v.2, p.319.

[2] B.Yu.Sharkov et al., "Heavy ion fusion activities at ITEP", Nucl. Insr. \& Methods in Phys. Res., A415 (1998) 20-26

[3] N.N.Alexeev et al. "Simulation of Accumulation Process in ITEP-TWAC", EPAC98, p.1141.

[4] N.N.Alexeev et al. "Beam dynamics in matching channel of ITEP-TWAC Heavy Ion Injector I-3", EPAC2000, p.1283.

[5] V.A.Krasnopolsky et al., "The ITEP-TWAC Injection and Extraction Kicker", PAC99, TUP2. 